\title{
Techniques of Enhancing Induced Secondary Voltage
}

\author{
R. Subrahmanyam \\ Department of Physics, JNTU, Ananthapur, Andhra Pradesh, India
}

Received: March 10, 2017; Accepted: April 25, 2017; Published: May 17, 2017

*Corresponding author: R. Subrahmanyam, Retd. Professor \& Head, Department of Physics, JNTU, Ananthapur, Andhra Pradesh, India, E-mail: rsubbu65@gmail.com

\begin{abstract}
Two cylindrical copper coils (inductors) are kept one inside the other. A ferromagnetic cylindrical road (core) is kept inside the inner coil. AC voltage given to the inner coil (primary) induces voltage in the outer coil (secondary). The amount of voltage induced is given by faraday's law of induction. It is observed that instead of using a single primary coil if multiple primaries are used and the same voltage applied to the single primary is applied to all primaries connected in series, the voltage induced in the secondary increases while the current through the primary decreases. This saves a lot of electrical energy. Detailed studies on the use of multiple primaries are reported in this paper. This Principle is used to redesign the transformer.
\end{abstract}

Keywords: Induced secondary voltage; Ferro magnetic Core; Inductance; Primary Coil; Secondary Coil

\section{Introduction}

The author is investigating several techniques to get more induced secondary voltage than given by Faradays law. He observed that the induced secondary voltage in an iron cored copper coil can be increased 1. By increasing the temperature of the core and 2. By enclosing the iron cored coil in an aluminium tube $[1,2]$. Another method for increasing induced secondary voltage by using multiple primaries is described in this paper.

\section{Description of Experimental Setup}

\section{Primaries}

APoly vinyal chloride cylindrical tube of length $22 \mathrm{cms}$ and diameter $4 \mathrm{~cm}$ is wound with an insulated copper wire of gauge number 19. Ten CRGO laminations of rectangular in shape are passed through the tube. The width, thickness and length of lamination are $3.8 \mathrm{cms}, 0.3 \mathrm{cms}$ and $50 \mathrm{~cm}$. These act as cores. This entire assembly act as primary. This is shown in figure $1 \mathrm{six}$ such primaries are assembled. The DC resistance of each coil is $0.8 \mathrm{ohms}$. The AC impedance of each coil is $4.2 \mathrm{ohms}$.

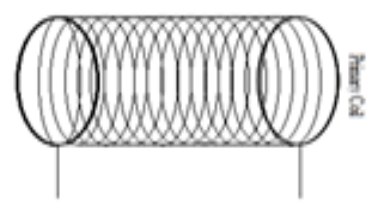

Figure 1: Primary Coil

\section{Secondary}

A Poly vinyal chloride tube of length $22 \mathrm{cms}$ and diameter $16 \mathrm{cms}$ is wound with an insulated copper wire of gauge number 26.The number of turns are 500. This is shown in figure 2. The DC resistance of the secondary is $22.4 \mathrm{ohms}$. The AC impedance of the secondary is $130 \mathrm{ohms}$.

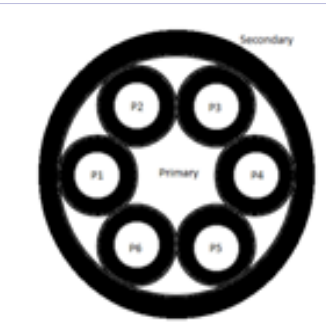

Figure 2: Secondary Coil

All the six primary coils are kept inside the secondary. The 10 CRGO laminations in each tube are connected end to end. As the ends are connected they enclose the secondary turns also. This is shown in figure 3. This is repeated for the remaining five coils. 


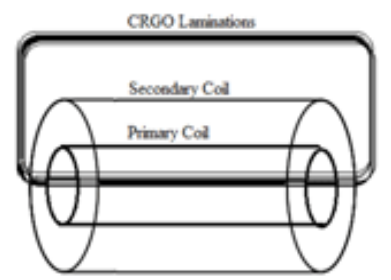

Figure 3: Arrangement of Primary and Secondary Coils

\section{Load}

A Poly vinyal chloride tube of length $22 \mathrm{cms}$ and diameter $8 \mathrm{~cm}$ is wound with an insulated copper wire of gauge number 28. The DC resistance of the coil is $12 \mathrm{ohms}$. The AC impedance of the coil is $13 \mathrm{ohms}$.

The voltage to primary coils is supplied by a variac of $220 \mathrm{~V}$ and 15 amps. The voltages and currents in primary and secondary circuits are measured using digital multimeter.

\section{Experimental Procedure}

Measurement of Induced Secondary Voltage and Current
AC voltage $\left(V_{p}\right)$ is applied to single primary coil $P_{1}$. The primary current $I_{p}$, the secondary voltage VS and the secondary current IS are measured. $\mathrm{I}_{\mathrm{p}}$ ' is the primary current corresponding to the secondary current $\mathrm{I}_{\mathrm{S}^{\prime}}$. The second primary $\mathrm{P}_{2}$ is connected in series with the first primary $\mathrm{P}_{1}$. The same primary voltage is applied to the combination of $\mathrm{P}_{1}$ and $\mathrm{P}_{2}$. The corresponding primary current $I_{p}$, secondary voltage $V_{S}$ and the secondary current $I_{S}$ are measured. The procedure is repeated for the remaining four primary coils.

\section{Measurement of Load Voltage and Load Current}

The load inductor is connected in series with the secondary. A voltage $V_{P}$ is given to the primary coil $P_{1}$. The primary current $I_{P}$ the load voltage $V_{L}$ and current through load $\mathrm{I}_{\mathrm{L}}$ are measured. The above procedure is repeated for primaries $\left(\mathrm{P}_{1}+\mathrm{P}_{2}\right),\left(\mathrm{P}_{1}+\mathrm{P}_{2}+\mathrm{P}_{3}\right),\left(\mathrm{P}_{1}+\mathrm{P}_{2}+\mathrm{P}_{3}+\mathrm{P}_{4}\right),\left(\mathrm{P}_{1}+\mathrm{P}_{2}+\mathrm{P}_{3}+\mathrm{P}_{4}+\mathrm{P}_{5}\right)$, $\left(\mathrm{P}_{1}+\mathrm{P}_{2}+\mathrm{P}_{3}+\mathrm{P}_{4}+\mathrm{P}_{5}+\mathrm{P}_{6}\right)$.

\section{Measurement of Power Factor}

Open circuit and short circuit tests are performed for all the primaries connecting one by one in series.

\section{Observations \& Calculations}

\begin{tabular}{|c|c|c|c|c|c|c|c|c|c|c|}
\hline Core Number & $\mathrm{V}_{\mathrm{P}}$ (volts) & $I_{p}$ (Amperes) & $\mathrm{V}_{\mathrm{s}}($ volts $)$ & $I_{s}$ (Amperes) & $I_{p}^{\prime}$ (Amperes) & $\cos \phi$ & $\begin{array}{c}P_{P}=V_{P} I_{P} \\
\cos \Phi(\text { watts) }\end{array}$ & $P_{\mathrm{P}}^{\prime}=\mathrm{V}_{\mathrm{P}} \mathrm{I}_{\mathrm{P}}{ }^{\prime} \cos \Phi($ watts $)$ & $\begin{array}{c}\alpha=P_{p} / V_{s} \\
\text { (jouls/ } \\
\text { volt) }\end{array}$ & $\begin{array}{c}\beta=\mathrm{P}_{\mathrm{P}}^{\prime} / \\
\mathrm{I}_{\mathrm{s}} \text { (jolus/ } \\
\text { Ampere) }\end{array}$ \\
\hline $\mathrm{P}_{1}$ & 15 & 12.17 & 15.8 & 0.0151 & 11.8 & 1 & 190.5 & 177 & 12.05 & 11800 \\
\hline $\mathrm{P}_{1}+\mathrm{P}_{2}$ & 15 & 3.94 & 33.0 & 0.037 & 3.9 & 0.57 & 33.687 & 33.34 & 0.7 & 901 \\
\hline $\mathrm{P}_{1}+\mathrm{P}_{2}+\mathrm{P}_{3}+\mathrm{P}_{4}$ & 15 & 0.59 & 49.7 & 0.4 & 1.62 & 0.79 & 6.99 & 19.2 & 0.14 & 48 \\
\hline $\mathrm{P}_{1}+\mathrm{P}_{2}+\mathrm{P}_{3}+\mathrm{P}_{4}+\mathrm{P}_{5}$ & 15 & 0.23 & 51.5 & 0.52 & 1.94 & 0.65 & 2.24 & 18.9 & 0.043 & 36.34 \\
\hline $\mathrm{P}_{1}+\mathrm{P}_{2}+\mathrm{P}_{3}+\mathrm{P}_{4}+\mathrm{P}_{5}+\mathrm{P}_{6}$ & 15 & 0.15 & 52.5 & 0.59 & 2.11 & 0.41 & 0.922 & 12.97 & 0.017 & 1.56 \\
\hline
\end{tabular}

In Table I is shown the variation of $I_{P}, V_{S}, I_{S}$ and $I_{p}{ }^{\prime}$ as the primary cores are increasing from $\mathrm{P}_{1}$ to $\mathrm{P}_{6}$ for a primary voltage of 15 volts. The power in the primary $\mathrm{P}_{\mathrm{P}}$ is calculated using the formula $\mathrm{PP}=\mathrm{V}_{\mathrm{PIPcos} \Phi}$. The ratio between $\mathrm{P}_{\mathrm{P}}$ and $\mathrm{V}_{\mathrm{S}}$ gives the primary power required to produce one volt in the secondary. This is represented by $\alpha$. Similarly $\beta$ is the primary power required to get a current of 1ampere in secondary.

In Table II is shown variation of IP, VS, IS and IP' with variation of primary voltage for a single primary coil P1 similar results for 4 and 6 primaries are shown in Tables III and Table IV.

In Table $\mathrm{V}$ is shown the variation of IP, VL and IL with variation of cores from 1 to 6 for a primary voltage of 15.5 volts. The load resistance is $52 \Omega$. The input power PIN and output PL is calculated as shown in the table. The ratio of PL to Pin gives efficiency and it is also shown in the Table V.

In Table VI and Table VII are shown the results of OC and $\mathrm{SC}$ tests for all the earlier combination of cores.

Table II: Variation of Vs \& Is with Vp for single primary

\begin{tabular}{|c|c|c|c|}
\hline $\mathbf{V}_{\mathbf{p}}$ (volts) & $\mathbf{I}_{\mathbf{p}}$ (Amperes) & $\mathbf{V}_{\mathbf{s}}$ (volts) & $\mathbf{I}_{\mathbf{s}}$ (Amperes \\
\hline 1.51 & 0.066 & 5.27 & 6.2 \\
\hline 4.5 & 1.15 & 12.7 & 12.3 \\
\hline 10.13 & 7.1 & 15.2 & 1.03 \\
\hline 15.1 & 11.9 & 15.4 & 7.0 \\
\hline
\end{tabular}


Table III: Variation of Vs \& Is with Vp for four primary cores

\begin{tabular}{|c|c|c|c|c|}
\hline$V_{P}($ volts $)$ & $I_{\mathrm{p}}$ (Amperes) & $\mathrm{V}_{\mathrm{s}}$ (volts) & $I_{s}$ (Amperes) & $I_{P}{ }^{\prime}($ Amperes) \\
\hline 1.64 & 27.7 & 5.5 & 11.1 & 63.7 \\
\hline 1.49 & 61.7 & 16.56 & 28.3 & 157 \\
\hline 10.2 & 153 & 34.5 & 171.5 & 0.73 \\
\hline 15.15 & 0.56 & 49.1 & 0.37 & 1.5 \\
\hline 20.1 & 1.39 & 61.5 & 0.63 & 2.6 \\
\hline 25.1 & 2.66 & 70.0 & 0.89 & 3.73 \\
\hline 31.6 & 4.60 & 73.2 & 1.2 & 5.3 \\
\hline 41.1 & 7.44 & 76.1 & 1.63 & 7.7 \\
\hline 52.5 & 10.54 & 78.5 & 1.96 & 10.52 \\
\hline
\end{tabular}

Table IV: Variation of $V_{s} \& I_{s}$ with $V_{p}$ for six primary cores

\begin{tabular}{|c|c|c|c|c|}
\hline$V_{P}$ (volts) & $I_{\mathrm{P}}$ (Amperes) & $\mathrm{V}_{\mathrm{s}}$ (volts) & $I_{s}$ (Amperes) & $I_{\mathrm{P}}{ }^{\prime}$ (Amperes) \\
\hline 1.6 & 0.0214 & 5.6 & 0.0432 & 0.1532 \\
\hline 4.1 & 0.0408 & 14.1 & 0.1051 & 0.46 \\
\hline 10.5 & 0.0851 & 35.4 & 0.41 & 1.49 \\
\hline 15.3 & 0.15 & 52.4 & 0.6 & 2.14 \\
\hline 20.4 & 0.38 & 69.2 & 0.81 & 2.92 \\
\hline 25.7 & 0.9 & 84.6 & 1.02 & 3.7 \\
\hline 30.5 & 1.4 & 97.9 & 1.25 & 4.54 \\
\hline 35.1 & 2.19 & 108 & 1.45 & 5.23 \\
\hline 40.2 & 3.16 & 114 & 1.66 & 6.00 \\
\hline 50.7 & 5.17 & 118 & 2.12 & 7.7 \\
\hline 60.1 & 6.87 & 121 & 2.46 & 9.03 \\
\hline
\end{tabular}

Table V: Variation of Efficiency with Primary Cores for a Load Resistance of 52 Ohms

\begin{tabular}{|c|c|c|c|c|c|c|c|}
\hline No of Coils & $\mathrm{V}_{\mathrm{P}}$ (volts) & $I_{P}($ Amperes $)$ & $\begin{array}{c}P_{\text {in }}=V_{P} I_{P} \\
\cos \Phi(\text { watts })\end{array}$ & $\mathrm{V}_{\mathrm{L}}$ (volts) & $I_{L}$ (Amperes) & $P_{L}=V_{L} I_{L}$ (watts) & $\eta=P_{L} / P_{E}$ \\
\hline $\mathrm{P}_{1}$ & 16.9 & 17 & 100 & 0.809 & 0.0159 & 0.12 & 1.2 \\
\hline $\mathrm{P}_{1}+\mathrm{P}_{2}$ & 19.7 & 8.06 & 100 & 2.08 & 0.0414 & 0.0886 & 8.6 \\
\hline $\mathrm{P}_{1}+\mathrm{P}_{2}+\mathrm{P}_{3}$ & 26.3 & 6.67 & 100 & 14.77 & 0.29 & 4.3 & 4.3 \\
\hline $\mathrm{P}_{1}+\mathrm{P}_{2}+\mathrm{P}_{3}+\mathrm{P}_{4}$ & 31.4 & 5.55 & 100 & 31.1 & 0.61 & 18.9 & 19 \\
\hline $\mathrm{P}_{1}+\mathrm{P}_{2}+\mathrm{P}_{3}+\mathrm{P}_{4}+\mathrm{P}_{5}$ & 34.2 & 4.67 & 100 & 42.1 & 0.84 & 35.36 & 35 \\
\hline $\mathrm{P}_{1}+\mathrm{P}_{2}+\mathrm{P}_{3}+\mathrm{P}_{4}+\mathrm{P}_{5}+\mathrm{P}_{6}$ & 34.3 & 4.24 & 100 & 45.6 & 0.89 & 40.6 & 40 \\
\hline
\end{tabular}

Table VI: Open circuit test for multiple primary coils

\begin{tabular}{|c|c|c|c|c|}
\hline No of Coils & $\mathbf{V}_{\text {oc }}$ (volts) & I $_{\text {oc }}$ (amperes) & Power \\
\hline 2 & 33.6 & 13.74 & 0.57 \\
\hline 3 & 35.6 & 9.37 & 264 \\
\hline 4 & 37.3 & 6.44 & 190 \\
\hline 5 & 38.4 & 4.4 & 0.79 \\
\hline 6 & 39.3 & 3.1 & 0.65 \\
\hline
\end{tabular}


Table VII: Short circuit test for multiple primary coils

\begin{tabular}{|c|c|c|c|}
\hline No of Coils & $\mathbf{V}_{\text {sc }}$ & $\mathbf{I}_{\text {sc }}$ & Power \\
\hline 1 & 11.4 & 8.5 & 100 \\
\hline 2 & 24.1 & 9.07 & 200 \\
\hline 3 & 25.8 & 5.6 & 100 \\
\hline 4 & 26.4 & 4.34 & 100 \\
\hline 5 & 26.5 & 4.27 & 100 \\
\hline 6 & 26.6 & 4.22 & 100 \\
\hline
\end{tabular}

\section{Results}

Table I shows that $\alpha$ and $\beta$ are decreasing as the number of cores are increasing. The electrical power required producing 1 volt and $1 \mathrm{amp}$ current in secondary are decreasing with increase of cores. For example in case of a single core 2.67 watts of power in primary is required to produce 1 volt in secondary. This power is reduced to 0.008 watts for six cores.

As seen from Tables II, Tables III and Tables IV the range of operation before saturation is increasing as primary cores are increasing. The maximum voltage for a single core is 15.2 volts, for four cores 52.5 volts and for six cores 85 volts.

Table V shows that the power transferred to the load increases as the number of cores are increasing (The primary is remaining constant). The efficiency increases with multiple cores.

\section{Conclusions}

Thus by using multiple cores the voltage induced in the secondary and the power delivered to the load increases compared to single core. This increase in output voltage and current is obtained not by increasing input electrical power but by decreasing the input electrical power. This helps to save lot of electrical energy. This principle can be applied to transformers thereby saving larger amounts of electrical energy.

\section{References}

1. R.Subrahmanyam. Temperature coefficients of permeability and induced EMF in ferro magnetic Material. J.pure\& Appl. Phys. 2009;21(2):273-280.

2. R.Subrahmanyam. Effect of Aluminium Enclosures on Induced EMF. Procedia Materials Science. 2014;6:444-449 